\title{
Prevalence of HPV types in Jordanian women with abnormal pap smear
}

\author{
M. Bishtawi ${ }^{1}$, H. Saleh ${ }^{2}$, M. Khadra ${ }^{3}$. \\ ${ }^{1}$ Al Ahli Hospital, Obstetrics and Gynecology, Doha, Qatar. \\ 2Sidra medicine, Obstetrics and Gynecology, Doha, Qatar. \\ ${ }^{3} J o r d a n$ University Hospital, Obstetrics and Gynecology, Amman, Jordan.
}

\section{Objectives:}

Infection with high-risk HPV (HR-HPV) is the main cause of cervical cancer. However, little is known about its prevalence in the female population in Jordan. The aim of this study was to discover HPV type-specific prevalence in women living in Jordan

\section{Methods:}

abnormal smears had reflex HPV testing from apparently healthy and nonhealthy women. HPV prevalence and its genotype distribution were examined in these smears. DNA samples were extracted and HPV genotyping was performed.

\section{Results}

A total of 209 abnormal Pap smears were identified; 153 (73.2\%) of the tested cases were HPV positive. The mean age of the women included was 38.3 years and the mean age of HPVpositive women was 38.5 years. There was a significant increase in the incidence of HPV infection over the study period. HPV 6 and 11 infections were common in the HPV positive women; $38.6 \%$ and $47 \%$, respectively. HPV 16 was the single most common (57.5\%) HPV infection detected. HPV 30's (31,33, 34, 35, and 39) as a group were the most common HPV infections recorded at $59.5 \%$. HPV 50's $(51,52,53,56,58$, and 59) were detected in $56.9 \%$ of the cases. HPV type 68 was recorded in one case $(0.6 \%)$

\section{Conclusions:}

The results of the study showed a relatively high prevalence (73.2\%) of HPV infection and a higher incidence of co-infection with multiple high risk genotypes (89\%) in comparison with other studies from the present region. This study suggests that there is sufficient evidence to warrant further population-based studies and further interventions
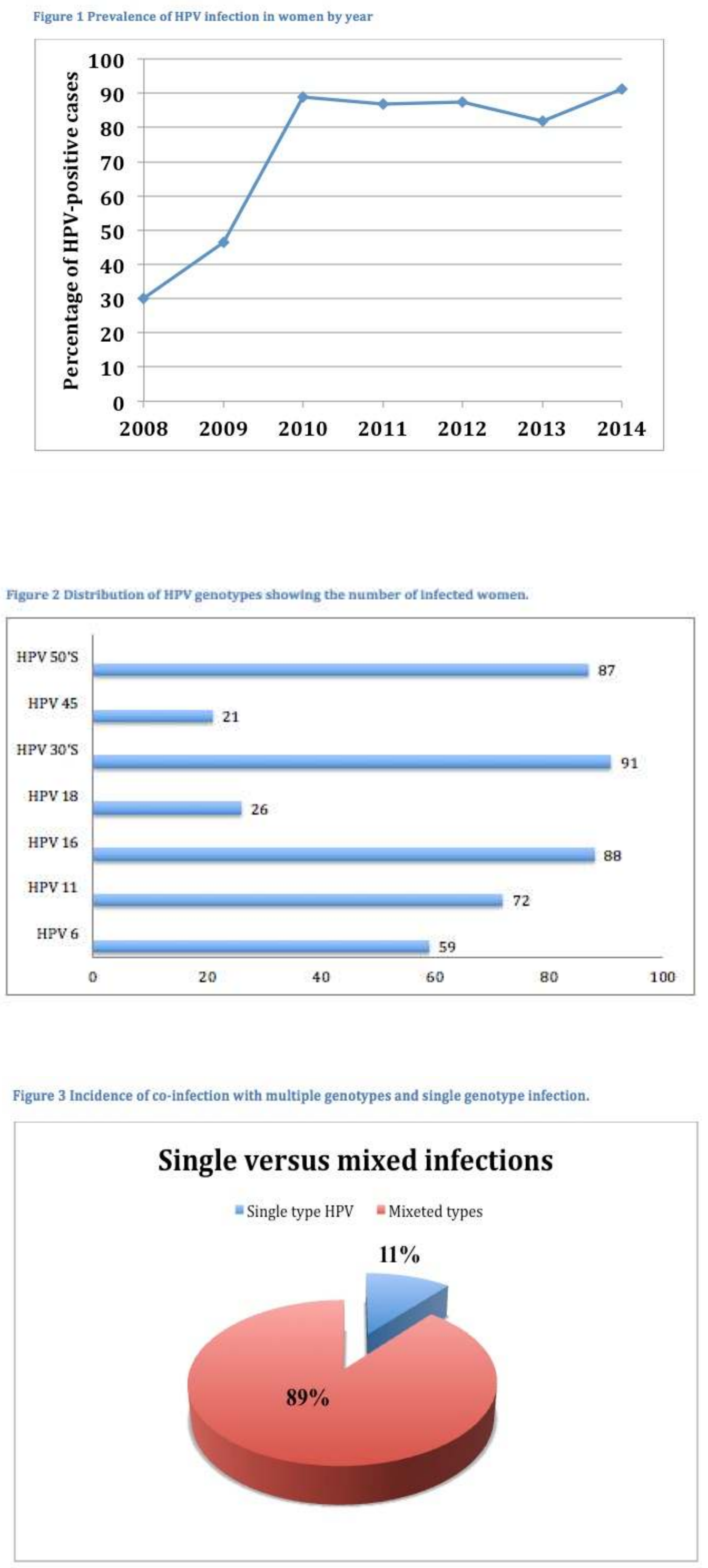

References

1. Burd EM. Human papillomavirus and cervical cancer. Clin Microbiol Rev. 2003;16(1):1-17.

2. de Sanjose S, Quint WG, Alemany L, Geraets DT, Klaustermeier JE, Lloveras B, et al. Human papillomavirus genotype attribution in invasive cervical cancer: a retrospective cross-sectional worldwide study. Lancet Oncol. 2010;11(11):1048-56.

3. Clifford GM, Gallus S, Herrero R, Munoz N, Snijders PJ, Vaccarella S, et al. Worldwide distribution of human papillomavirus types in cytologically normal women in the International Agency for Research on Cancer HPV prevalence surveys: a pooled analysis. Lancet. 2005;366(9490):991-8.

4. Khan MJ, Partridge EE, Wang SS, Schiffman M. Socioeconomic status and the risk of cervical intraepithelial neoplasia grade 3 among oncogenic human papillomavirus DNA-positive women with equivocal or mildly abnormal cytology. Cancer. 2005;104(1):61-70. 